working on advanced materials and developing microelectronics. It is thought that a few workers will be offered posts at Wembley, where fundamental work in this line is carried out, but GEC already has a well established group working on materials science. There is also a group at Harlow which is just getting going onto production engineering and automation, and it is feared that the GEC is just not interested in this.

It is highly likely that a similar story would emerge from the Blackheath laboratories, but GEC is trying to restrain comment. The statement that the company is to build up powerful research teams, particularly at Wembley, is being received with scepticism by some of those affected.

\section{New Man at Harwell}

Dr Walter Marshall is to succeed Dr Robert Spence as director of the Atomic Energy Research Establishment at Harwell on April 1. One of his principal tasks will be to supervise the practical and commercial assist. ance which the establishment hopes to give to industry in Britain.

Dr Marshall, who is 35, joined the AERE in 1954 and became head of its theoretical physics division in 1960. He was appointed deputy director in 1966. Dr Spence became head of the chemistry division at Harwell in 1946 and has been director since 1964. $\mathrm{He}$ now goes to the University of Kent to take up the mastership of the new third college, as yet unnamed, and the chair of applied chemistry.

\section{New Man in France}

THERE is great pleasure in France that the new head of the Délégation Générale de la Recherche Scientifique et Technique is Dr Pierre Aigrain, until this week in charge of higher education at the Ministry of Education. Dr Aigrain is 43 and is a physicist by origin and since 1959 has been secretary-general of the French Physical Society. His career has alternated spells in government departments with intervals of academic life. He has, for example, held scientific positions with the French navy, the atomic energy commission (CEA) and, most recently, the army. He was at the Collège de France for a brief spell in the early fifties and has been connected with the universities of Lille and Paris. He has won himself a high reputation as an energetic and sensible man.

\section{Physics Information}

THE American Institute of Physics has landed the first instalment of a grant from the National Science Foundation which is likely to amount to more than a million dollars in the next five years and which will be spent on the study and development of new techniques in the dissemination of information in physics. Work has already begun on the project, which was described at the New York meeting of the American Physical Society at the end of January by Dr H. W. Koch, director of the American Institute of Physics. Like the American Chemical Society, the American Institute of Physics, which is a federation of several learned societies ranging in size from the American Physical Society to the Society of Rheology (with a few hundred members), has come to occupy a central position in the publication of original material in physics. Dr Koch said that the institute's journals have been publishing more than 50,000 pages in aggregate each year for several years now. The total size of all its journals seems in fact to be doubling every five years. The American Institute of Physics is perhaps more outspoken than other similar organizations in its belief that there would be benefits in devices which could replace formal publication.

The plan for the information study now begun will cover several aspects of this problem. For one thing, there is to be a thorough study of the uses of computers in the storage and retrieval of information. In this sense, the Institute of Physics will be following the Chemical Abstracts Service, which is now publishing lists of titles on magnetic tape. It seems, however, to be acknowledged that physicists may not be as well served by computer storage as are the chemists-for one thing the costs of tape retrieval seem to be high and informal exchanges of preprints among interested groups of physicists have been well developed. But the Institute of Physics is also hoping to tackle directly the qualitative problems of the scientific literature, and the programme of work ahead is to include a serious attempt to decide what part formal articles in the scientific journals should play in the dissemination of information. A convincing answer would be well worth a million dollars.

\section{Doctorates in the United States}

A statistical report on the education and subsequent employment of PhD students and their equivalent in the United States has been published by the National Academy of Sciences for the Office of Scientific Personnel of the National Research Council (Doctorate Recipients from United States Universities, 1958-1966). The source of all the information is the Documents Records File which is compiled from extremely detailed surveys of graduates completing doctoral degrees. This file goes back to 1920 and must surely be the envy of higher education authorities in other countries for its thoroughness. All subjects are covered in the report, though there is no doubt about the predominance of science and technology. In 1966, a total number of 17,865 graduates received doctorates, of which 6,077 (34.02 per cent) were in physical sciences and engineering, and 2,869 (16.06 per cent) were in biological sciences. A further 2,666 (14.92 per cent) were awarded doctorates in the social sciences. Altogether there has been an average growth rate of $9 \cdot 2$ per cent over the period 1958-66. Engineering has had the most spectacular increase-in 1966, four times as many doctorates were given in this field as in 1958 . Corresponding to the growth in numbers of $\mathrm{PhDs}$ are figures for the growth in numbers of colleges and universities. There is also a detailed analysis of the pattern of doctoral education-the time taken to register for higher degrees after completion of first degrees, transference from one course to another and from one institution to another during the period of study and so on.

Of interest to the followers of the Swann and Willis Jackson reports on scientific and technical manpower are the analyses of postdoctoral employment. Colleges and universities are the main employers of higher degree graduates in all fields, and a greater percentage 